\title{
THE SEXIST OCCUPATIONAL REPRESENTATION IN ENGLISH TEXTBOOKS OF IRANIAN HIGH SCHOOLS
}

\author{
Masoumeh BAHMAN \\ University of Malaya \\ bahmanmasoumeh@gmail.com
}

Manuscript received 18 July 2020

Manuscript accepted 6 October 2020

*Corresponding author

https://doi.org/10.33736/ils.2431.2020

\begin{abstract}
The present study aims to investigate the occupational roles assigned to women and men in three volumes of English textbooks of Iranian high schools (Birjandi, Soheili, Nowruzi, \& Mahmoodi, 2006) using Hartman and Judd's (1978) framework. The results of the inferential and descriptive analyses demonstrated that these textbooks were $99 \%$ sexist in regards to occupational roles as men were depicted in high-status jobs, but women were represented in low-status jobs. In addition, men were manifested in a greater range of occupations than women.
\end{abstract}

Keywords: Gender; occupational roles; sexism; stereotypical occupations

\section{Introduction}

The present study aims to investigate the occupational roles assigned to women and men in three volumes of English textbooks of Iranian high schools (Birjandi, Soheili, Nowruzi, \& Mahmoodi, 2006) using Hartman and Judd's (1978) framework. The results of the inferential and descriptive analyses demonstrated that these textbooks were $99 \%$ sexist in regards to occupational roles as men were depicted in high-status jobs, but women were represented in low-status jobs. In addition, men were manifested in a greater range of occupations than women. In another study, Kobia (2009) investigated the manifestation of gender images in English textbooks of primary school in Kenya and found that women were underrepresented in editorship, photography, authorship and typesetting, and that men appeared more than women in photographs, illustrations, titles and names. Bahman and Rahimi (2010) studied three volumes of English textbooks of Iranian high schools (Birjandi et al., 2006) in terms of male-generics, firstness, names, nouns, pronouns and adjectives attributed to women and men and found that these textbooks were sexist as they did not deal with males and females fairly and women 
were under represented and had low visibility. Roohani and Zarei (2013) examined a pre-university English textbook in terms of female and male names, pronouns, nouns, pictures, and readings attributed to females and males and found that the Iranian pre-university English textbook was male-oriented and gender-biased.

Ghajarieh and Salimi (2016) blended Kress and van Leeuwen's (2006) social network model and Sunderland's (2006) gendered discourses model and examined the representations of male and female social actors in school books. Ghajarieh and Salimi (2016) found that "as for Iran, the discourse of equal opportunities in education should be highlighted along with other subversive gendered discourses" (p. 267). Cocoradă (2018) analysed curriculum materials including textbooks and supplies, and two Romanian fairy tales and confirmed negative discrimination against women.

\section{Socio-cultural Context in Iran}

Gender ideologies are prevailing in Iran in which women are considered as secondclass citizens (Mir-Hosseini, 2006). Discrimination against women originates from the political ideology that has been imposed on Iranian women since the establishment of the Islamic Republic and "Iran has become for many the epitome of a retrogressive patriarchal society" (Higgins \& Shoar-Ghaffari, 1991, p. 213). The socio-political context existing in Iran leads to gender bias. Gender discrimination against women is also present in English textbooks used in Iran as "language is ideological in nature" (Ahour \& Zaferani, 2016, p. 80).

\section{Biased Occupational Roles}

Women and men are represented in different roles in any society as Thorne and Henley $(1975$, p. 20$)$ believe "every society uses sex, to one degree or another, in allocating tasks, activities, rights, and responsibilities" (p. 20). Similarly, men and women are manifested in various occupational roles in EFL materials. "Occupational visibility" is defined as "... nomenclature for men and women in relation to occupations, professions, offices and related positions (Pauwels, 1998, p. 230). Hartman and Judd (1978) believe that "the most pervasive sexism... is the shunting of women and men into stereotypical roles" (p. 385), as stereotypical roles assigned to women are usually household work like, baking, cooking washing polishing, mending, cleaning, sewing, and child care.

Furthermore, the occupational roles of women and men represented in ELT textbooks are not fair because men are mainly manifested in high-status roles like lawyer, surgeon, or scientist but women are often depicted in low-status occupational roles such as secretary, nurse or schoolteacher (Hellinger \& Bubmann, 2002). Martyna states that the occupational roles such as doctor, lawyer and engineer refer to males, but, secretary and nurse and model refer to females (as cited in Thorne, Kramarae, \& Henley, 1983). The representation of women in stereotypical roles in EFL textbooks has considerable impact on learners, and also strengthens the stereotypical beliefs as Otlowski (2003) declares "this depiction of 
women in such stereotypical roles only helps to reinforce the outdated notion that women stay at home and men go out to work" (p. 2).

Women are associated with stereotypical occupational roles as mothers whose job is to stay at home, bring up children or do household chores (Amini \& Birjandi, 2012; Thorne \& Henley, 1975). Similarly, Porreca (1984) found that "occupations for women are often restricted in the traditional service and entertainment jobs, such as waitress, nurse, secretary, and actress, occasionally including a token professional job such as teacher or doctor" (p. 719). Mills (1995) claims that "professors, scientists and engineers tend to be labelled as necessarily male, and nurses, librarians, secretaries and models as females" (p. 88).

Another area of occupational sexism is that men are depicted in a greater range of occupational roles (Hellinger, 1980). Hartman and Judd (1978) found that males were depicted in more various occupations than women, for instance, males were represented in the jobs of student, policeman, doctor, professor of Spanish, ambassador, store manager, landlord, flight controller, stock boy, media anchor man, real estate agent, school principal, ambulance driver, tow truck operator, pilot, army general, senator, priest, motel manager, but jobs such as nurse, bank employee, housewife, student, salesgirl and stewardess were assigned to females. In English language teaching textbooks taught in Germany, women were often depicted in having fewer occupational choices than men (Hellinger, 1980). In a study carried out by Farooq (1999), females were represented in more unstable and limited jobs such as part timer or stewardess and males were represented in the jobs considered as "responsible and respectable such as prime minister, employer, and editor" (p. 17). Harashima (2005) examined one college-level English textbook and found that three occupations were allocated to males, but no jobs were assigned to females. Also, in the study carried out by Hamid, Yuen, Othman, Yasin, and Baharuddin (2013), females were depicted in 13 professions while males were represented in 33 types of professions.

Another form of occupational sexism is that different job titles are used for both females and males although the work is the same (Sunderland, 2006). Positively connoted job titles are used for males and the job titles that have less positive connotations are used for females, for example, the title "office manager" is used for males, but, the title "typing supervisor" is used for females (Sunderland, 2006, p. 35).

\section{Methodology}

This study aimed to investigate English textbooks of Iranian high schools (Birjandi et al., 2006) in relation to occupational roles using Hartman and Judd (1978) as Hartman and Judd (1978) investigated a sample of ESL textbooks which had been published over a period of 12 years providing guidelines for examining sexism in textbooks. In order to find out whether women and men were represented equally in regards with occupations in in these textbooks, all parts of the textbooks as well as the illustrations were investigated. The occupational roles of the males and females or the jobs differentiating males and females were identified. Consider these examples: (1) She is a teacher; (2) The man who is repairing the car is a 
mechanic (Birjandi et al., 2006). In some cases, it had not been mentioned whether the person having a certain kind of occupation was a female or male in the texts. However, the drawings or illustrations gave a clue that it was a female or male. So, with the help of the drawings and illustrations it was decided whether it should be counted as a female or a male, for example, in the sentence, (3) What does a photographer do?, the illustration shows a man with a camera, so, this occupation has been considered as an occupation for males (Birjandi et al., 2006).

According to the occupational roles for both females and males in these textbooks, the frequency of each of the occupational roles was also identified. The study employed both qualitative and quantitative approaches in which frequency counts of occupational roles for females and males were counted. After the tabulation of the raw data, they were converted to statistical data. Chi-squares were utilised to statistically get the frequencies of the raw data. A questionnaire (Bahman, 2008) was also distributed among 25 Teaching English as a Foreign Language (TEFL) graduate students of Alzahra University. A total of 25 TEFL students were chosen as they were all studying English Teaching for their Masters and were also English teachers who were teaching English at various language schools. There were 25 respondents who met the researcher's criteria: i) proficient in English, and ii) English teachers. The students using these textbooks were not chosen as they were not proficient in English.

Initially, the researcher had prepared the questions asking about the occupational roles in the questionnaire in an open way, that is, the researcher had not given the occupations for the respondents. The respondents, themselves, were expected to write the occupations for females and males. The results showed that there were 68 occupational roles for males and 46 occupational roles for females. However, later on, as a result of a consultation with an SPSS expert, it was decided that the occupational roles should be chosen from English textbooks of Iranian high schools (Birjandi, et al., 2006) by the researcher herself. Thus, considering these three textbooks, 19 occupations were found and a new questionnaire was developed and administered to the aforementioned participants again. These students were asked to choose what occupations they believed were more natural for females, males or both females and males in EFL materials.

\section{Results and Discussion}

Table 1 shows the occupational roles of males and females in the three volumes collectively. The numbers in parentheses show the percentages, and the ones in square brackets represent the instances. $N$ shows the number of different occupational roles. In Figure 1, the distribution of the frequency of the occupational roles of females and males is shown. 
Table 1

Number of Instances of Males and Females Portrayed in Occupational Roles in Volumes 1, 2 \& 3 Collectively

\begin{tabular}{|c|c|c|c|c|}
\hline Sex & & Male & & male \\
\hline & Instances & Different roles & Instances & Different roles \\
\hline & & Athlete[3] & & Housewife[4] \\
\hline & & Bus-driver[2] & & Nurse[1] \\
\hline & & Clerk[2] & & Servant[11] \\
\hline & & Doctor[4] & & Teacher[5] \\
\hline & & Driver[1] & & \\
\hline & $71(77.2)$ & Farmer[7] & 21 & $\mathrm{~N}=4$ \\
\hline & & Mechanic[5] & (22.8) & \\
\hline & & Miner[1] & & \\
\hline & & Photographer[1] & & \\
\hline & & Pilot[1] & & \\
\hline & & Policeman[10] & & \\
\hline & & Sailor[1] & & \\
\hline & & Shopkeeper[2] & & \\
\hline & & Teacher[18] & & \\
\hline & & Thief[1] & & \\
\hline & & Waiter[12] & & \\
\hline & & $N=16$ & & \\
\hline
\end{tabular}

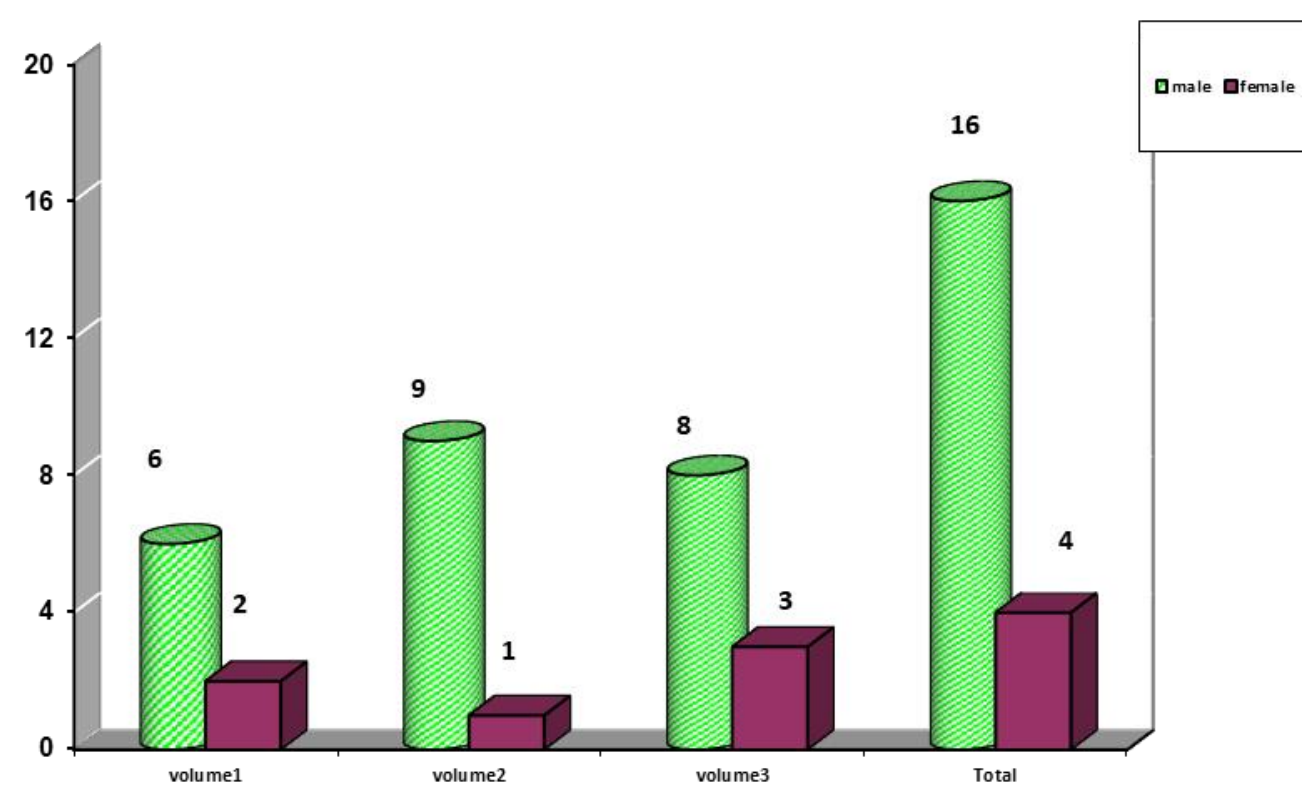

Figure 1. Distribution of the frequency of the occupational roles of males and females in volumes 1, 2 \& 3 of English textbooks of Iranian high schools 
It can be observed that the total frequency of the occupational roles of males is more than females in the volumes 1, 2, and 3 of the aforementioned textbooks. In other words, the total frequency of the occupational roles of males, i.e. 16 is more than females, i.e. four in the three volumes. Males were found to have 16 different occupations, but females had only four different roles. Therefore, more occupations were attributed to men than women. To confirm these results, Chi-squares test was used.

The distribution of the frequency of the occupational roles of males is more than females and $d f=1$ and alpha=0.01 is statistically significant. Therefore, with $99 \%$ certainty, it can be stated that there is a statistically significant difference between the frequency of the occupational roles of males and females in volumes 1, 2 and 3 of these textbooks and the preference is given to males. To confirm the results above, 25 graduate students of TEFL at Alzahra University were given a questionnaire to choose the occupational roles referring to males, females or both of them. The analysis of the data as shown in Table 2, revealed that more than 11 occupations were allocated to men, but, for women at the very most, two occupations were considered. As it can be observed in Table 2, these two occupations were "housewife" and "nurse". It was also found that the frequencies of six other occupations are almost the same for both genders.

Table 2

Occupational Roles in the Questionnaire

\begin{tabular}{ccccc}
\hline No. & Occupation & Female & Male & Female/Male \\
\hline 1 & Athlete & 0 & 17 & 8 \\
2 & Bus driver & 1 & 22 & 2 \\
3 & Clerk & 2 & 6 & 17 \\
4 & Doctor & 1 & 4 & 20 \\
5 & Driver & 0 & 25 & 0 \\
6 & Farmer & 0 & 22 & 3 \\
7 & Housewife & 25 & 0 & 0 \\
8 & Mechanic & 0 & 25 & 0 \\
9 & Miner & 0 & 25 & 0 \\
10 & Nurse & 20 & 0 & 5 \\
11 & Photographer & 0 & 8 & 17 \\
12 & Pilot & 0 & 21 & 4 \\
13 & Policeman/Policewoman & 0 & 20 & 5 \\
14 & Sailor & 0 & 25 & 0 \\
15 & Servant & 7 & 6 & 12 \\
16 & Shopkeeper & 1 & 9 & 15 \\
17 & Teacher & 10 & 0 & 15 \\
18 & Thief & 0 & 23 & 2 \\
19 & Waiter/Waitress & 1 & 16 & 8 \\
\hline
\end{tabular}

The Sexist Occupational Representation in English Textbooks of Iranian High Schools 
There was also an investigation on whether there is a statistically significant difference between the frequencies of each of the occupational roles of females and males in English textbooks of Iranian high schools. For this, first, the results of descriptive statistics were presented, and then inferential statistics of Chi-square test were analysed. Table 1 shows the frequencies of each of the occupational roles in volumes 1, 2, and 3 collectively. In figure 2, the distributions of the frequencies of each of the occupational roles of females and males are depicted. As it can be observed, the frequencies and the percentages of each of the occupational roles of males in volumes 1,2 , and 3 collectively are more than females, that is, the total percentage of the frequencies of each of the occupational roles of males, i.e. $77.2 \%$ is more than those of females, i.e. $22.8 \%$.

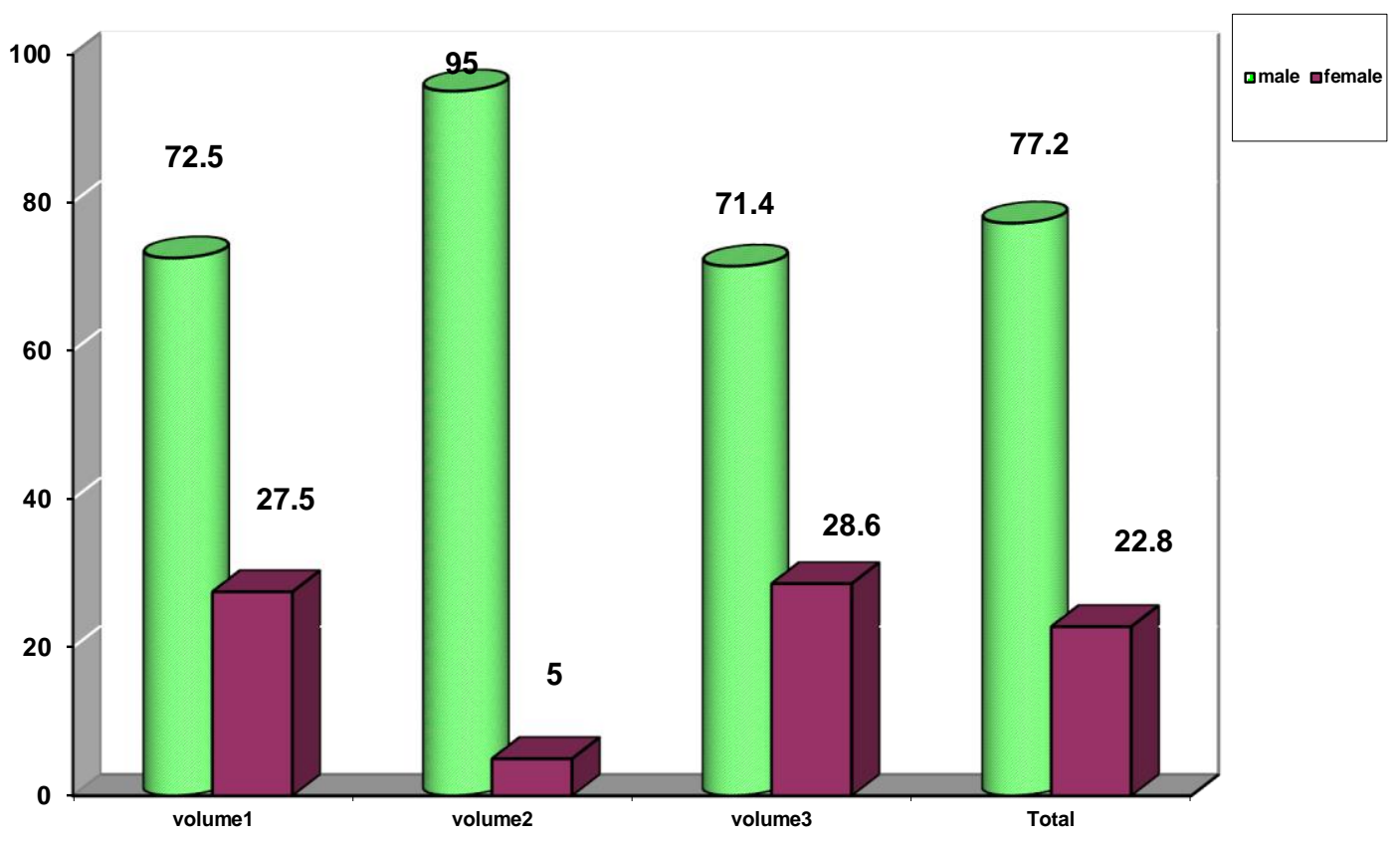

Figure 2. Distribution of the frequency of each of the occupational roles of females and males in the volumes 1, 2, and 3 collectively

To confirm the results, the outcome of Chi-square test shows that Chisquares with $\mathrm{df}=1$ and alpha $=0.01$ are statistically significant. Therefore, with $99 \%$ certainty, it can be stated that there are statistically significant differences between the frequencies of each of the occupational roles of females and males in the three volumes of the text books investigated. As it was mentioned earlier, in EFL materials, males and females are represented in different occupational roles. In other words, stereotypically women are represented in low-status occupations such as secretary and nurse (Mills, 1995) or schoolteacher (Hellinger \& Bubmann, 2002) and men are shown in high-status occupations e.g., pilot, policeman (Hartman \& Judd, 1978) or doctor (Martyna, as cited in Thorne, Kramarae, \& Henley, 1983). In the three volumes of English textbooks of Iranian high schools it was also found that women 
were represented in stereotypical occupations such as "nurse", "housewife", and "teacher", and men were found in stereotypical occupations "doctor", "policeman" and "pilot".

\section{Pedagogical Implications}

The results of the present study have obvious importance for TEFL and especially for writing EFL materials, so the issues of gender and language should be given more attention in order to abolish sexist language present in the EFL textbooks. As a teacher and researcher, I have felt the gender gap between females and males in EFL materials and more specifically in Iranian EFL textbooks.

Sexist language can be eradicated in many different ways, some of which are as follows: 1) Both females and males should be given equal space in materials, 2) Both females and males should be assigned non-sexist occupations, 3) Genderinclusive or gender-neutral terms can be introduced, e.g., police officer or firefighter, 4) Gender issues can be made salient for the language learners. We can do this by discussing sexism and other gender- related issues with the learners, and 5) Text books writers should be provided with non-sexist language guidelines.

\section{Conclusion}

This study investigated and analysed occupational roles and stereotypical occupations of females and males in English textbooks of Iranian high schools. For this purpose, three English textbooks which were used in grades 1, 2 and 3 in Iranian high schools were examined in detail. The results demonstrated that there were occupational biases in these series of textbooks in which women and men were not fairly depicted in regards to occupations. Men were manifested in more various occupational roles than females and also high- status jobs were assigned to men, but, females were depicted in limited and mundane stereotypical occupations such as teacher, nurse and secretary. The findings of this research may have implications on gender awareness to foster gender equality in EFL textbooks so that materials developers will try to produce gender-free materials in which females and males are manifested fairly and equally especially in the occupational roles. Sexism, including language and gender issues can be further studied and investigated in other EFL textbooks used in secondary schools of Iran, EFL textbooks commonly used in language institutes, and English textbooks used in the universities in Iran. In addition, dialogues of EFL textbooks in terms of amount of talk or lengths of speakers' utterances can be scrutinised in order to find out whether females and males have more or less equal parts in conversations or not.

\section{References}

Ahour, T., \& Zaferani, P. (2016). A critical visual analysis of gender representation of ELT materials from a multimodal perspective. The Journal of Applied Linguistics, 9(18), 78-98.

The Sexist Occupational Representation in English Textbooks of Iranian High Schools 
Amini, M., \& Birjandi, P. (2012). Gender bias in the Iranian high school EFL textbooks. English Language Teaching, 5(2), 134-147.

Bahman, M. (2008). Gender representation in EFL materials: An analysis of English textbooks of Iranian high schools (Unpublished master's thesis). Alzahra University, Tehran, Iran.

Bahman, M., \& Rahimi, A. (2010). Gender representation in EFL materials: An analysis of English textbooks of Iranian high schools. Procedia Social and Behavioral Sciences, 9, 273-277.

Birjandi, P., Soheili, A., Nowruzi, M., \& Mahmoodi, G. H. (2006) English book (Vols. 1, 2 \& 3). Tehran: Printing and Publishing Company of Iran Textbooks.

Cocoradă, E. (2018). Gender stereotypes in school textbooks. Revista Romaneasca Pentru Educatie Multidimensionala, 10(4), 65-81. https://doi.org/10.18662/rrem/73

Emilia, E., Moecharam, N. Y., \& Syifa, I. L. (2017). Gender in EFL classroom: Transitivity analysis in English textbooks for Indonesian students. Indonesian Journal of Applied Linguistics, 7(1), 206-214.

Farooq, M. U. (1999). Examining sexism in an EFL textbook. Retrieved from http://www.cels.bham.ac.uk/resources/essays/farooq6.pdf

Ghajarieh, A., \& Salimi, A. (2016). Gendered representations of male and female social actors in Iranian educational materials. Gender Issues, 33, 258-270.

Hall, M. (2014). Gender representation in current EFL textbooks in Iranian secondary schools. Journal of Language Teaching and Research, 5(2), 253261.

Hamid, B. A., Yuen, C. K., Othman, Z., Yasin, M. S. M., \& Baharuddin, J. H. (2013). A corpus-based investigation of gender stereotyping and linguistic sexism in Qatari primary school science textbooks. Pertanika Journal of Social Sciences \& Humanities, 21(S), 197-218.

Harashima, H. D. (2005). Sexual bias in an EFL textbook: A case study. In K. Bradford-Watts, C. Ikeguchi \& M. Swanson (Eds.), JALT 2004 Conference proceedings (pp. 1005-1011). Tokyo: JALT.

Hartman, P. L., \& Judd, E. L. (1978). Sexism and TESOL materials. TESOL Quarterly, 12(4), 383-393.

Hellinger, M. (1980). For men must work, and women must weep: Sexism in English language textbooks used in German schools. In C. Kramerae (Ed.), The voices and words of women and men (pp. 267-274). New York: Pergamon Press.

Hellinger, M., \& Bubmann, H. (2002). Gender across languages: The linguistic representation of women and men. In M. Hellinger \& H. Bubmann (Eds.), Gender across languages: The linguistic representation of women and men (pp. 2-25). Philadelphia: John Benjamins.

Higgins, P. J., \& Shoar-Ghaffari, P. (1991). Sex-role socialization in Iranian textbooks. NWSA Journal, 3(2), 213-232.

Kobia, J. M. (2009). Femininity and masculinity in English primary school textbooks in Kenya. The International Journal of Language Society and Culture. Retrieved from http://www.educ.utas.edu.au/users/tle/JOURNAL/28-6.pdf Lakoff, R. (1973). Language and women's place. New York: Harper and Row. 
Lee, J. F. K. (2014). A hidden curriculum in Japanese EFL textbooks: Gender representation. Linguistics and Education, 27, 39-53.

Mills, S. (1995). Feminist stylistic. London: Routledge.

Mir-Hosseini, Z. (2006). Muslim women's quest for equality: Between Islamic law and feminism. Critical Inquiry, 32(4), 587-601.

Otlowski, M. (2003). Ethnic diversity and gender bias in EFL textbooks. Asian EFL Journal, 5(2), 1-9. Retrieved from http://www.asian-efljournal.com/june_03_mo.p

Pauwels, A. (1998). Women changing language. London: Longman.

Porreca, K. L. (1984). Sexism in current ESL textbooks. TESOL Quarterly, 18(4), 705724.

Roohani, A., \& Zarei, M. (2013). Evaluating gender-bias in the Iranian preuniversity English textbooks. Indonesian Journal of Applied Linguistics, 3(1), 115-125.

Sakita, T. I. (1995). Sexism in Japanese English education: A survey of EFL texts. Woman and Language, 18, 5-12.

Salami, A., \& Ghajarieh, A. (2016). Culture and gender representation in Iranian school textbooks. Sexuality \& Culture, 20, 69-84. doi: 10.1007/s12119-0159310-5

Sunderland, J. (2006). Language and gender. London: Routledge.

Thorne, B., \& Henley, N. (1975). An overview of language, gender, and society. In B. Thorne \& N. Henley (Eds.), Language and sex: Difference \& dominance (pp. 5-42). Rowley: Newbury.

Thorne, B., Kramarae, C., \& Henley, N. (1983). Language, gender and society: Opening a second decade of research. In B. Thorne, C. Kramarae \& N. Henley (Eds.), Language, gender and society (pp. 7- 24). Rowley: Newbury.

Vahdatinejad, S., \& Hamid, B. A. (2017). Linguistic sexism in the Iranian EFL junior high school textbooks. Journal of Advance Research in Social Science and Humanities (JIAATS), 3(2), 1-19.

Weiss, R. P. (2001). Gender biased learning. Training \& Development, 55(1), 42-48. 